\title{
Experiências na Extensão Universitária: Reabilitação de Amputados
}

\author{
Experiences in University Extension: \\ Rehabilitation Amputees
}

\author{
Kadine Priscila Bender dos Santos ${ }^{I}$ \\ Soraia Cristina Tonon da Luz
}

\section{PALAVRAS-CHAVE}

- Extensão Universitária;

- Reabilitação;

- Amputação;

- Promoção da Saúde;

- Educação Médica.

\section{KEYWORDS}

- University Extension;

- Rehabilitation;

- Amputation;

- Health Promotion;

- Medical Education.

Reencaminhado em: 02/12/2014

Aprovado em: 08/08/2015

\begin{abstract}
RESUMO
Este estudo relata as atividades do Projeto de Extensão Reabilitar e Integrar: Reabilitação Multidisciplinar em Amputados, da Universidade Estadual de Santa Catarina (Udesc), integradas à Rede de Atenção à Saúde. Pretende-se divulgar a experiência e os métodos aqui utilizados para aprimorar o processo de ensino-aprendizado que visa a uma formação profissional atenta à promoção da saúde da população em questão. Apresenta-se o projeto e descreve-se o desenvolvimento teórico-prático dos objetivos, ações e recursos empregados em sua execução, a fim de oferecer uma revisão e reflexão que contribuam para um enfoque na reabilitação integral de pessoas amputadas. Este projeto se traduz como uma oportunidade de a Instituição de Ensino Superior (IES) contribuir com a Rede de Atenção à Saúde da pessoa que sofreu amputação, reduzindo os riscos de morbidade com ações de promoção, prevenção e prática multidisciplinar, e aprimorando as habilidades e competências de discentes e profissionais da saúde.
\end{abstract}

\section{ABSTRACT}

This study aims to report the extension activities of the Rehabilitation and Integration Outreach Project: Multidisciplinary Amputee Rehabilitation of the State University of Santa Catarina (UDESC) integrated into the Health Care Network. The intention is to share the experience and methods used to enhance the education process aimed at a vocational training that promotes health among the population in question. This paper presents the project and describes the theoretical-practical development of the objectives, actions and resources used in its execution, in order to offer a review and reflection that contribute toward a focus on comprehensive rehabilitation of amputees. This project can be translated as an opportunity for the Higher Learning Institute (IES) to contribute to the Health Care Network of amputees, reducing the risk of morbidity with health promotion and prevention practices and multidisciplinary practice, as well as enhancing the skills and competences of health care professionals and students. 


\section{INTRODUÇÃO}

O presente artigo tem como objetivo demonstrar a importância das atividades extensionistas nas IES voltadas à promoção da saúde e que se articulam com a rede de saúde. Este artigo descreve a prática do Projeto Reabilitar e Integrar da Universidade Estadual de Santa Catarina (Udesc), com enfoque na reabilitação de pacientes com amputação de membros inferiores, e traz uma descrição sistemática do desenvolvimento teórico-prático dos objetivos, ações e recursos utilizados na execução do projeto.

Trata-se de um modo de discutir a extensão universitária sem se ater somente aos conceitos, à descrição de suas práticas, auxiliando, assim, em sua concepção de maneira mais clara. Para isto, inicialmente parte-se da premissa de que, até os dias atuais, a extensão universitária suscita questionamentos quanto a sua concepção, sendo que em alguns momentos estas discussões passam a ser rotuladas como repetitivas. Enquanto forem classificadas com este viés, fica reforçada a necessidade de avaliações e mais esclarecimentos ${ }^{1}$.

Reabilitar uma pessoa amputada não significa necessariamente protetizá-la. Entretanto, para pacientes candidatos à utilização de próteses, a reabilitação só chegará ao fim quando eles já estiverem fazendo uso das próteses, com total controle e independência nas atividades diárias, profissionais e recreativas. Para alcançar esta reabilitação completa, é necessária uma equipe multiprofissional e interdisciplinar, para que o indivíduo tenha um atendimento integral com médicos, fisioterapeutas, protéticos, psicólogos, nutricionistas e assistentes sociais, entre outros ${ }^{2}$.

O acompanhamento fisioterápico deve ser realizado antes e após a colocação das próteses a fim de diminuir e eliminar estados dolorosos, modelar o coto, reduzir edemas, impedir e eliminar contraturas, treinar equilíbrio, potencializar os grupos musculares debilitados, impedir deformidades secundárias, melhorar a sensibilidade, realizar treinamento adequado de marcha e corrigir vícios posturais ${ }^{3,2}$.

Para que os pacientes que sofreram amputação de membros inferiores possam readquirir uma marcha normal, com movimentos rítmicos, alternados e com o mínimo de esforço, a reabilitação deve ser realizada o mais precocemente possí$\mathrm{vel}^{4,5,6}$. Reconhece-se a importância da assistência emocional a amputados de diferentes níveis no período que sucede a amputação. E também que a percepção desfavorável da autoimagem corporal pode conduzir a pessoa amputada a sentimentos de inferioridade e ansiedade, que devem ser amenizados pelos profissionais de saúde com a estimulação do paciente para o autocuidado ${ }^{7,8}$.

A amputação, de modo geral, constitui um processo traumático para o indivíduo, que precisa buscar reencontrar-se psicológica e socialmente. Todo o processo de reabilitação pode transcorrer de forma rápida e eficaz, obtendo o indivíduo grande funcionalidade e independência na utilização de suas próteses; ou, pelo contrário, podem-se observar falhas na reabilitação, que, por sua vez, comprometem o indivíduo em grau variável.

$\mathrm{Na}$ ausência dos segmentos corporais, como numa amputação, o coto é o responsável por receber as adaptações sensório-motoras específicas advindas de exigências como a locomoção, assegurando aferências somatossensoriais para a manutenção do equilíbrio e possibilitando o desenvolvimento da marcha com prótese? .

\section{O projeto de extensão e sua integração à Rede de Atenção}

O projeto de extensão Reabilitação Multidisciplinar em Amputados, vinculado ao Programa Reabilitar e Integrar da Udesc, busca proporcionar, mediante avaliações físico-funcionais, com enfoque biomecânico, a prescrição de um plano de tratamento específico para usuários do Sistema Único de Saúde (SUS) que sofreram amputação.

Várias são as repercussões que uma amputação pode acarretar na integridade do sistema sensório-motor de um sujeito, o que pode impactar diretamente sua independência funcional e qualidade de vida. Conhecendo-se o padrão da marcha com prótese, a postura e a sensibilidade do coto, pode-se programar um atendimento específico e individualizado de acordo com o contexto em que ocorreu a amputação (traumática, tumoral, etc.). Com esta atenção, busca-se contribuir para a independência funcional, dinamismo e força muscular, o que pode facilitar o retorno do sujeito a diversas atividades em todas as esferas: profissional, social, emocional, de esporte e de lazer.

Com referência à conexão entre ensino, pesquisa e extensão, as atividades se relacionam com os três pilares que constituem a Udesc. As atividades de atendimento multidisciplinar ao público-alvo (pessoas que sofreram amputação) são atividades de ensino, visto que os acadêmicos e os professores mantêm uma relação de ensino-aprendizagem, ao mesmo tempo em que executam as ações de extensão da universidade. Além disso, estimulam a pesquisa, pois há atividades de extensão do projeto relacionadas à aplicação das técnicas / condutas por meio de pesquisas que envolvem a construção de protocolos específicos. E todos os dados dos pacientes atendidos, após os projetos terem aprovação do Conselho de Ética e Pesquisa, são organizados num banco de dados, que pode gerar futuras produções científicas.

Além de realizar avaliações físico-funcionais com enfoque biomecânico, o projeto proporciona avaliações multidis- 
ciplinares com enfoque em pessoas que sofreram amputação (avaliação da marcha, da sensibilidade do coto, da sobrecarga com acelerometria, avaliação postural); proporciona a vivência prática dos conhecimentos fisioterapêuticos e de educação física mediante elaboração do plano de atendimento individual ao público-alvo envolvido nesta ação específica; promove o atendimento específico, buscando melhorar a independência funcional e a postura dos sujeitos com cinesioterapia para fortalecimento do coto e membro íntegro e grupos musculares estabilizadores da postura; promove atendimento específico em busca de melhorar o padrão de marcha e independência funcional dos sujeitos (subida e descida de escadas e rampas); busca melhorar ou minimizar a sensibilidade do coto, adequar/treinar as descargas de cargas distribuídas na prótese e no membro íntegro; proporciona a vivência prática multidisciplinar (envolvimento de dois cursos -Fisioterapia e Educação Física) por meio de atendimentos supervisionados às pessoas que sofreram amputação; promove o aprimoramento acadêmico através do estudo dos casos clínicos atendidos; promove capacitação dos discentes por meio de treinamentos periódicos durante a execução do programa.

Entretanto, por mais que este projeto proporcione tais ações, observa-se grande demanda de pacientes sem reabilitação, além da carência de estudos que viabilizem uma Rede de Atenção à Saúde da pessoa que sofreu amputação. Vemos este projeto como uma oportunidade de a IES traçar uma rede de atenção integral à saúde da pessoa que sofreu amputação, reduzindo os riscos de morbidade por intermédio da implementação de ações de promoção, prevenção e prática multiprofissional com possibilidade de aprimoramento das habilidades e competências de discentes e profissionais da saúde.

É desconhecido o impacto da morbidade nos acidentes de trânsito gerado por uma amputação em termos de utilização da estrutura de saúde, tipos de cuidados e tempo de afastamento necessário à reabilitação dessas vítimas. Também se desconhecem os resultados para o indivíduo em seu contexto biopsicossocial.

Partindo desta premissa, este projeto de extensão almeja uma prática voltada a um conjunto de ações propostas às pessoas amputadas mediante condutas articuladas, que visam atender o sujeito individualmente ou em grupo após uma discussão coletiva da equipe interdisciplinar, que conta com apoio matricial. Neste projeto, há a tentativa de construir e aplicar uma proposta de Rede de Atenção à Saúde da pessoa que sofreu amputação através da formação de serviços e da organização de ações que busquem a integralização sistêmica do cuidado, oferecendo-se uma atenção pautada em princípios organizativos e doutrinários do SUS.
Isto porque compreende a necessidade de adentrar o campo da Atenção Primária (APS) por meio do fortalecimento das unidades de APS, das ações de promoção à saúde e da prevenção à saúde da pessoa amputada. É indispensável uma atenção especializada, e esta é ofertada por intermédio do serviço prestado pelo projeto de extensão e também pelo serviço de notificação hospitalar que este realiza nos hospitais do SUS da cidade de Florianópolis. A atenção no ambiente hospitalar caracteriza-se pela notificação do paciente em pós-operatório imediato ao projeto de extensão, entrega de um kit em formato de bolsa contendo um manual de orientação, uma faixa elástica para o enfaixamento do coto e um cartão de agendamento para a primeira consulta no projeto de extensão. $\mathrm{O}$ paciente recebe o encaminhamento e é direcionado ao projeto, que tem sede no centro de referência estadual em protetização.

O projeto inclui a abordagem no leito hospitalar, com o acompanhamento precoce dos pacientes amputados, destacando os cuidados pós-operatórios imediatos; realização de exercícios preventivos; posicionamento correto; autonomia sustentável para atividades de vida diária (AVDs) com enfoque multiprofissional e contribuição para um fluxo de encaminhamento entre os serviços municipais de saúde e o Programa de Extensão Reabilitação e Integrar do Cefid/Udesc, que constitui um apoio para o referido centro de reabilitação.

No ambiente ambulatorial, o serviço corresponde ao recebimento dos pacientes encaminhados via hospitalar e demais serviços de saúde. O objetivo é avaliar e tratar o indivíduo implementando ações integradas sobre os determinantes sociais da saúde, identificando os facilitadores e as barreiras mediante uma abordagem terapêutica de forma integral: reabilitação antes e depois da colocação da prótese do paciente, o que compreende a composição de escola de marcha para uma autonomia sustentável com a prótese para AVDs e para o retorno ao trabalho; utilização de familiograma, a fim de avaliar o funcionamento sistêmico da família da pessoa amputada, considerando pontos fortes, fragilidades e aspectos que podem influenciar suas interações; aplicação de grupo focal, proporcionando interação entre os pacientes e a possibilidade de ouvir seus pontos de vista - esta abordagem investigativa permitirá analisar as vozes deste grupo, abrindo a possibilidade de novas intervenções, focadas em suas reais necessidades.

Todas estas ações estratégicas para a construção de uma Rede de Atenção à Saúde (RAS) da população em questão se realizam por meio de atividades de ensino, pesquisa e extensão, e reuniões, oficinas e estudos em grupo. Ressalte-se que o apoio matricial é a tônica, pois uma equipe multiprofissional e interdisciplinar elabora e avalia as atividades. São preconizadas metodologias participativas de educação permanente 
(formação continuada) para a equipe, que é constituída de discentes dos cursos de Fisioterapia e Educação Física, docentes da Udesc, profissionais fisioterapeutas voluntários e outros parceiros, o que inclui uma associação para pessoas amputadas localizada na Espanha.

Também há confecção de materiais educativos e artigos, apresentação em eventos científicos e vinculação de profissionais através de dissertações de mestrado e tese de doutorado na área. O projeto de extensão Reabilitar e Integrar tem compromisso com a promoção da saúde da pessoa amputada e com a formação profissional nos três níveis de atenção e busca que as pessoas amputadas não fiquem em meio a uma peregrinação pelos serviços, mas encontrem na rede a reabilitação plena.

\section{Metodologia do projeto de extensão}

A metodologia do projeto abrange os itens estabelecidos na seguinte ordem: notificação do paciente nos hospitais; conversa no leito para entrega de kit e cartão de agendamento para a primeira consulta no projeto; acolhimento dos pacientes encaminhados ao projeto; agendamento de cada paciente; avaliação inicial do paciente para conhecer a história da amputação e de sua reabilitação; avaliação do coto da amputação: trofismo, sensibilidade, edema; avaliação físico-funcional: independência nas AVDs e avaliação postural; avaliação da marcha; execução dos atendimentos fisioterapêuticos através de cinesioterapia específica, treino de marcha, dessensibilização do coto; treino de equilíbrio e de descarga de peso na prótese; execução dos atendimentos para manutenção da simetria postural; estudo dos casos clínicos atendidos; reavaliações periódicas dos tratamentos/ações propostos; treinamento dos discentes relativo às abordagens e tratamentos realizados; treinamento dos discentes e membros do programa relativo a novas metodologias e equipamentos destinados às avaliações e tratamento; registro da evolução do paciente em arquivo específico após cada sessão realizada; composição da estatística mensal de atendimento; realização de grupo focal e terapias em grupos específicos por perfis dos pacientes (protetizados e não protetizados).

\section{CONCLUSÃO}

O perfil das amputações mudou muito nos últimos tempos, e observa-se avanço nas amputações causadas pelo trânsito, sobretudo de membros inferiores em indivíduos jovens.

As amputações são caracterizadas como situações que geram cuidado emergencial e de urgência, pois se trata de uma situação crítica, iminente, que não pode ser adiada, já que está em risco a vida do indivíduo. O município de Florianópolis, seguindo a tendência observada, sofre uma evolução crescente de aumento na mortalidade e morbidade relacionadas com acidentes de trânsito, pois não existe uma rede de saúde que possa acolher a pessoa que sofreu amputação desde os cuidados emergenciais e de urgência, o que dificulta uma reabilitação efetiva com retorno rápido às atividades de vida diária e atividade laboral.

A elaboração de um projeto de extensão que se articule com uma rede que estabeleça uma atenção integral e humanizada desde a internação hospitalar é primordial, pois a assistência iniciada precocemente pode conduzir à reabilitação integral.

O projeto suscita a possibilidade de um estudo transversal através de pesquisas bibliográficas, análise de prontuários, familiograma, grupos focais e entrevistas com os pacientes e equipe multiprofissional nas diversas atividades da rede de saúde do município de Florianópolis nos três níveis de atenção. Este projeto representa uma oportunidade de a IES contribuir com esta rede de atenção à saúde da pessoa que sofreu amputação, reduzindo os riscos de morbidade com ações de promoção, prevenção e prática multidisciplinar, aprimorando as habilidades e competências de discentes e profissionais da saúde, além de viabilizar pesquisas avaliativas tendo em vista protocolos específicos para reabilitação de pessoas amputadas.

\section{REFERÊNCIAS}

1. Sinha R, Van Den Heuvel WJ. A systematic literature review of quality of life in lower limb amputees. Disabil Rehabil. 2010. [Epub ahead of print]

2. Carvalho JA. Amputações de Membros Inferiores: Em Busca da Plena Reabilitação. São Paulo: Manole; 2003.

3. Short C. Biomechanical Approach Maximizes Amputee Rehabilitation. Biomech 2000; 22(1):67-69.

4. Edelstein JE. Avaliação e Manejo Protético. En: O'Sullivan SB, Schmitz TJ. Fisioterapia: Avaliação e Tratamento. 2 ed. São Paulo: Manole; 1993. p.465-92.

5. Thomson A, Skinner A, Piercy J. Fisioterapia de Tidy. São Paulo: Livraria Santos; 1992. p.78-95.

6. Bukowski E. Análise Muscular de Atividades Diárias. 1 ed. São Paulo: Manole; 2002.

7. Price M, Fisher K. How does Counseling Help People with Amputation? J Prosthet Orthot 2002; 14(3):102-6. Disponível em:<http://www.oandp.org/jpo/>.

8. Chini GCO. A amputação sob uma perspectiva fenomenológica. Ribeirão Preto; 2005. Mestrado [Dissertação] - Escola de Enfermagem de Ribeirão Preto, Universidade de São Paulo.

9. Tonon da Luz SC, Avila AOV, Oliveira TP, Andrade MC, Ventoza Lacunza C, Berral de la Rosa FJ. Valoración del daño corporal en amputados de miembros inferiores. Trauma Fundación Mapfre. 2010; 21:178-183. 


\section{CONTRIBUIÇÃO DOS AUTORES}

Kadine contribuiu na concepção, delineamento, redação e revisão do artigo. Soraia participou no delineamento, redação e revisão do artigo.

\section{CONFLITO DE INTERESSES}

Não há nenhum tipo de conflito de interesses.

\section{ENDEREÇO PARA CORRESPONDÊNCIA}

Kadine Priscila Bender dos Santos

Universidade do Estado de Santa Catarina

Rua Pascoal Simone, 358 CEP: 88080-350

Florianópolis, Santa Catarina

E-mail: kadinebender@hotmail.com 